\title{
Equipamento para determinação da erodibilidade e tensão crítica de cisalhamento do solo em canais de estradas
}

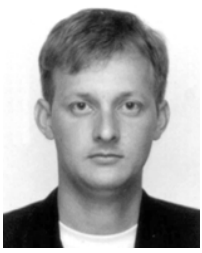

\author{
Nori P. Griebeler ${ }^{1}$, Fernando F. Pruski ${ }^{2}$, Herony U. Mehl ${ }^{3}$, Demetrius D. da Silva ${ }^{2}$ \& Luiz F. C. de Oliveira ${ }^{4}$ \\ 1 UFG/EA, Campus II, CEP 74001-970, Goiania, GO. CP 131 (62) 521-1534. E-mail: griebeler@yahoo.com.br (Foto) \\ 2 UFV/DEA. Av. P.H. Rolfs, S/N, CEP 36570-000. Viçosa, MG. E-mail: ffpruski@ufv.br; david@ufv.br \\ 3 INCRA, Av. Afonso Pena, 2403, CEP 79002-073, Campo Grande. E-mail: heronymehl@hotmail.br \\ ${ }^{4}$ UFG/EA. E-mail: Ifco@agro.ufg.br
}

Protocolo $78-6 / 5 / 2003$ - Aprovado em 5/7/2004

\begin{abstract}
Resumo: A erosão provocada pela água no leito e nas margens de estradas não-pavimentadas, está intimamente relacionada à má drenagem. Para que o sistema de drenagem seja feito de forma adequada, o conhecimento da erodibilidade e da tensão crítica de cisalhamento do solo é essencial. Neste sentido, desenvolveu-se um equipamento que permite a simulação do escoamento superficial e o acompanhamento das perdas de solo diretamente no leito ou no canal da estrada, possibilitando a determinação da tensão crítica de cisalhamento e da erodibilidade do solo. $O$ equipamento consiste em um conjunto composto por um reservatório de água, uma caixa de nível constante, uma calha para simulação do escoamento superficial e por um sistema de armazenamento da água escoada e filtragem dos sedimentos erodidos. Com base nos resultados obtidos com o uso do equipamento, constatou-se que este se mostrou satisfatório quanto aos aspectos de instalação, simulação de escoamento e quantificação de perdas para diferentes tensões aplicadas, permitindo a determinação da erodibilidade e da tensão crítica de cisalhamento do solo. No que tange à sua praticidade, o equipamento apresentou aspectos inconvenientes, sobretudo no que se refere à necessidade de mão-de-obra e consumo de água.
\end{abstract}

Palavras-chave: erosão em estradas, escoamento superficial, teste de erosão

\section{Equipment to determine erodibility and critical shear stress of soil in road channels}

\begin{abstract}
Water erosion on unpaved roads is directly related with poor drainage. The knowledge of the soil erodibility and critical shear stress is essential for correct design of drainage systems. In this paper equipment was developed which allows to simulate the surface runoff in the road channels and to determine, consequently, the soil erodibility and the critical shear stress for the soil. The equipment consists of a water reservoir, a box to control water level, a channel where the surface runoff simulation is made and a system to store the water and the sediments which are detached by surface runoff. The equipment had a good performance to determine the soil erodibility and the critical shear stress for the soil; however it has inconvenience with respect to labor and the amount of water necessary.
\end{abstract}

Key words: road erosion, surface runoff, erosion test

\section{INTRODUÇÃO}

Estradas podem ser definidas como faixas do terreno com características adequadas para permitir o deslocamento de pessoas e veículos devendo, para que possam cumprir sua função plenamente, se encontrar em condições favoráveis ao tráfego sob as mais variadas condições climáticas.

Um dos principais problemas que afetam a trafegabilidade das estradas não-pavimentadas é a sua degradação devido aos processos erosivos, afetando também áreas marginais e provocando prejuízos aos mais variados setores da economia e da sociedade. No Estado de São Paulo, conforme Anjos Filho (1998), essas estradas são responsáveis por aproximadamente metade das perdas de solo em virtude da erosão. Em áreas florestais, mais de $90 \%$ do sedimento produzido provêm das estradas, sendo este devido principalmente à drenagem inadequada (Grace III et al., 1998).

O leito das estradas deve apresentar características adequadas para suportar a carga a que será submetido sem que ocorra deformação capaz de modificar a conformação original 
do projeto. Deve também ser adequadamente drenada para que a umidade não altere suas características de resistência e a erosão não comprometa sua utilização. A drenagem da estrada é realizada por meio do seu abaulamento e da condução apropriada das águas retiradas do leito e daquelas advindas de áreas externas a esta, a qual normalmente é feita por meio de canais de drenagem.

O conhecimento da capacidade resistiva do solo ao escoamento superficial e as características deste escoamento são fundamentais para o correto dimensionamento do sistema de drenagem e do estabelecimento de medidas para o controle da erosão.

Quanto ao escoamento, o principal fator está relacionado à tensão cisalhante provocada por este e, quanto à resistência do solo, os fatores de maior importância são a erodibilidade e a tensão crítica de cisalhamento. A erodibilidade, conforme Bastos (1999), pode ser definida como a propriedade do solo que expressa a maior ou menor facilidade com que suas partículas são desprendidas por um agente erosivo, correspondendo à quantidade de solo desprendido por unidade de área, tempo e tensão aplicada; já a tensão crítica de cisalhamento dos solos pode ser entendida como a máxima tensão que pode ser aplicada ao solo sem que haja desprendimento de suas partículas, estando esta associada diretamente ao escoamento da água.

De acordo com Nogami \& Villibor (1995) a erodibilidade é um dos fatores mais importantes para a escolha do projeto mais apropriado para controlar a erosão ao longo das rodovias. Bastos (1999) salienta que a erodibilidade é uma das características mais complexas do solo, em virtude do grande número de fatores físicos, químicos, biológicos e mecânicos intervenientes. No Brasil, com relação ao estudo da erosão a erodibilidade do solo, constitui-se no parâmetro de maior custo e morosidade para determinação, tendo em vista a extensão do território e a diversidade de solos evidenciada no País (Denardin, 1990).

Bastos (1999) salienta que não existe um critério considerado unânime na literatura para a determinação da erodibilidade do solo. Este autor comenta, ainda, em seu trabalho, a respeito de diferentes ensaios para o estudo da resistência à erosão em solos coesivos. Um dos ensaios mais utilizados, quando se trata de erosão devido ao escoamento de água, é o de canais hidráulicos, cujos ensaios buscam reproduzir uma condição próxima à normalmente encontrada na natureza, simulando o escoamento da água de maneira controlada, sobre amostras de solo colocadas rente ao fundo de canais. Conforme Hollick (1976) a diferença entre a erodibilidade no canal e na amostra de solo, a incerteza na estimativa da tensão cisalhante e as imperfeições e má distribuição do escoamento na superfície da amostra, são os principais problemas associados ao uso dos canais hidráulicos. Kamphuis et al. (1990) preconizam a necessidade de extremos cuidados na moldagem das amostras empregadas nos testes em canais, devido à influência da estrutura natural dos solos na resistência à erosão, devendo ser evitada a formação de uma superfície que seja facilmente erodida e, também, a presença de descontinuidades que possam determinar o início do processo erosivo.

Um ensaio do tipo canal hidráulico, comumente utilizado no meio geotécnico, é o que utiliza o equipamento de Inderbitzen (Bastos, 1999). Neste equipamento, uma amostra de solo indeformada é presa à base de uma rampa, de modo que a superfície da amostra coincida com a superfície da rampa. A inclinação desta rampa pode ser alterada, bem como a vazão de escoamento, permitindo alterar as tensões cisalhantes aplicadas. Os resultados normalmente são expressos em gráficos de perda de solo por tempo. Fácio (1991) adaptou um equipamento de Inderbitzen visando à proposição de metodologia para estudo da erodibilidade dos solos do Distrito Federal. Bastos (1999) utilizou este equipamento para a determinação da erodibilidade e tensão crítica de cisalhamento de solos residuais da região de Porto Alegre, e Fragassi (2001) o utilizou para estudos da erodibilidade de solos residuais de gnaisse da Serra de São Geraldo e de Viçosa, em Minas Gerais.

Apesar da existência de diversos testes que possam fornecer a erodibilidade e a tensão crítica de cisalhamento do solo, o desenvolvimento de métodos diretos que reduzam a influência da técnica aplicada sobre o solo a ser testado e forneçam resultados confiáveis, é de suma importância para o dimensionamento de sistemas para controle da erosão. Por este motivo, desenvolveu-se um equipamento do tipo canal hidráulico, que permite simular o escoamento diretamente nos canais de drenagem das estradas, não sendo necessária a retirada de amostras.

\section{MATERIAL E MÉTODOS}

Para o desenvolvimento do equipamento procurou-se simular as condições naturais de escoamento, de maneira controlada, em uma área confinada diretamente sobre a superfície do terreno no campo, de modo que pudessem ser quantificados a tensão de cisalhamento aplicada e o tempo de aplicação.

\section{Descrição do simulador de escoamento}

$\mathrm{O}$ equipamento consiste de um conjunto para armazenamento e derivação de água $(5000 \mathrm{~L})$, um sistema para o controle do nível da água (500 L) e da vazão e uma calha construída com chapas metálicas, que permite a delimitação do trecho de canal a ser ensaiado. Apresenta ainda um sistema para condução, coleta e filtragem da água que passa pela calha e dos sedimentos erodidos. Na Figura 1A é apresentado um desenho esquemático do sistema. Na Figura 1B tem-se uma foto da calha no campo e, na Figura 2, um desenho da calha na qual ocorre o escoamento.

Para a fixação da calha, a parte inferior da lâmina metálica é biselada (Figura 2B-5) de modo que possa ser cravada no solo. As laterais da calha, no contato desta com o solo, são recobertas com espuma de alta densidade, de modo a reduzir a interferência da área do canal perturbada na instalação na perda de solo provocada. Desta forma, evita-se o contato direto do escoamento com esta área, conforme ilustrado na Figura 3A.

O desvio da água da superfície exposta do canal para a área de condução ao sistema de coleta é realizado por meio da colocação de uma placa de metal, com espessura de $1 \mathrm{~mm}$ e $20 \mathrm{~cm}$ de comprimento, sendo $5 \mathrm{~cm}$ dobrados em ângulo de $90^{\circ}$ (Figura 3B). A parte dobrada da placa é cravada no solo rente à junção da superfície exposta do canal com a área de condução do escoamento (Figura 2A, áreas 2 e 3 ). 
A.

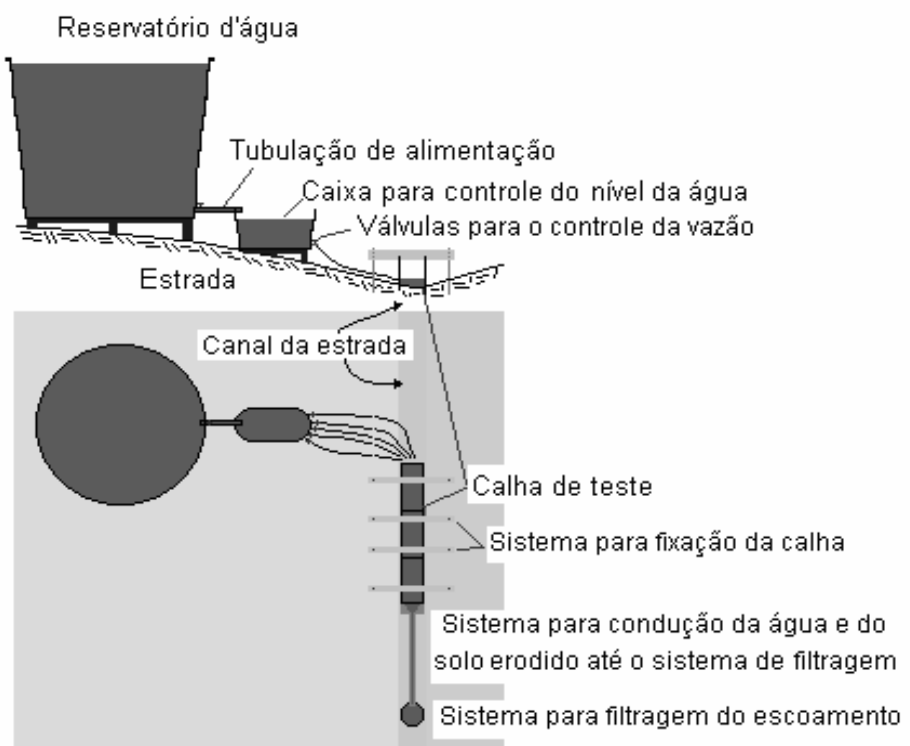

B.

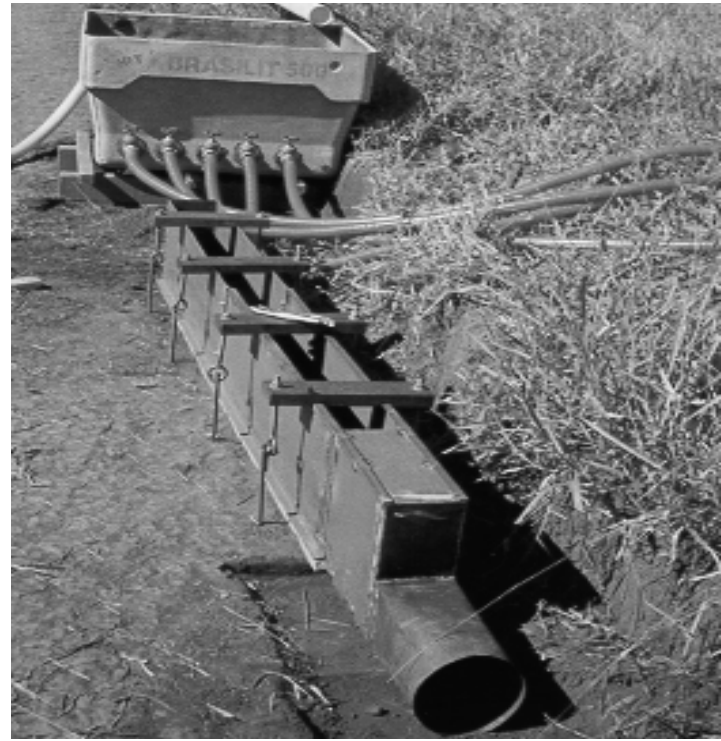

Figura 1. Desenho esquemático do sistema para determinação da tensão crítica de cisalhamento e da erodibilidade do solo em estradas não pavimentadas (A) e foto da calha para simulação do escoamento (B)

A.

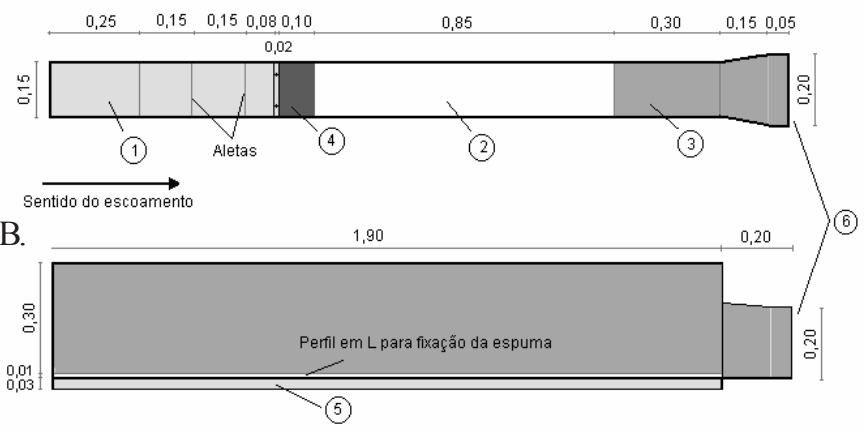

- Área da calha com fundo fechado com chapa metálica para permitir a aplicaçäo da água - Área da calha aberta, na qual o escoamento entra em contato com o solo do canal

- Área da calha, com fundo fechado, na qual o escoamento é direcionado para a tubulaçăo de saída - Pedaço de borracha flexível utilizado para fazer a ligação do escoamento do trecho 1 com o trecho 2 da calha - Lâmina biselada para permitir que a calha seja cravada no solo

Saída da tubulaçấo para conduçẫo da água ao sistema de armazenamento Medidas em metros

Figura 2. Desenho da calha para simulação do escoamento em canais de drenagem de estradas não pavimentadas: vista superior (A) e vista em perfil (B)

A calha apresenta, ainda, um sistema para sua fixação no solo e para reduzir a vibração quando da aplicação da água, conforme apresentado na Figura 4.

\section{Funcionamento do equipamento}

A água é derivada do sistema de armazenamento até a caixa, para controle de nível. Desta caixa, a água é lançada na área da calha com fundo fechado (Figura 2A-1). A turbulência causada pelo lançamento da água na calha é reduzida por meio de aletas colocadas perpendicularmente ao escoamento na área fechada da calha (Figura 2A-2). Na seqüência, a água escoa para a área vazada (Figura 2), onde entra em contato direto com o leito do canal. Desta área, a água é novamente direcionada para um trecho da calha com fundo fechado (Figura 2A-3), sendo então conduzida para a tubulação que direciona o escoamento para o sistema de armazenamento, localizado em cota inferior. Do sistema de armazenamento toda a água é filtrada.
A.

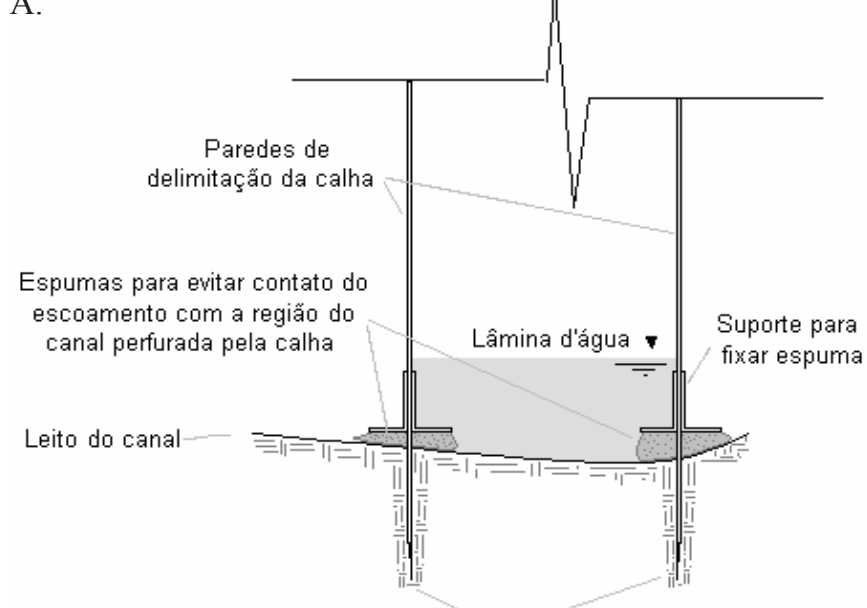

Lâminas cortantes para cravar a calha no solo

B.

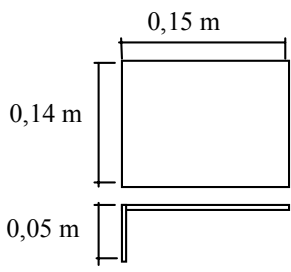

Figura 3. Corte transversal esquemático na calha do simulador de escoamento (A) e placa metálica para direcionamento do escoamento para a área de condução (B)

\section{Realização de testes com o simulador de escoamento}

Para realização dos testes no campo foi escolhida uma estrada não-pavimentada, localizada no campus da Universidade Federal de Viçosa, em Viçosa, MG. Para o solo do leito ensaiado foram obtidas as características apresentadas na Tabela 1.

A caixa para controle de nível, na qual é alterada a vazão lançada na calha, foi instalada sobre esta, utilizando-se um estrado de madeira devidamente nivelado. 
A.

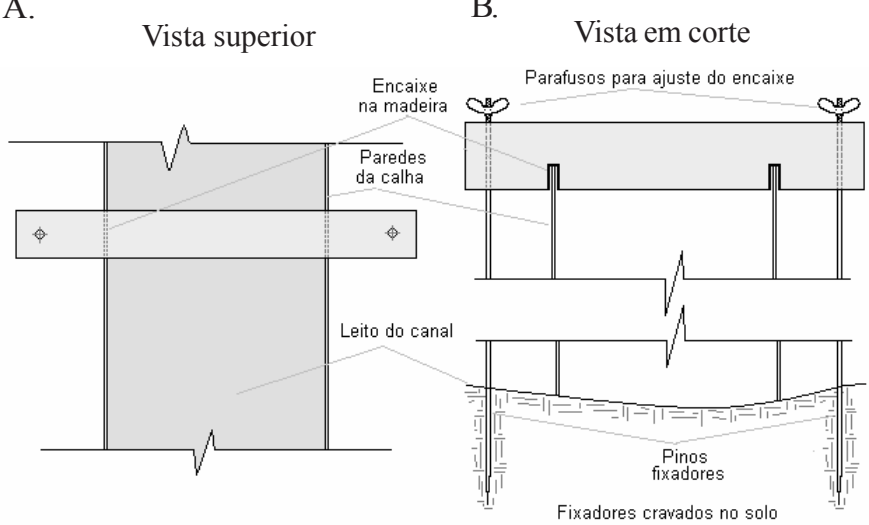

Figura 4. Desenho esquemático ilustrando os fixadores para evitar a vibração lateral da calha: vista superior (A) e vista em corte (B)

Tabela 1. Características físicas do solo do canal no qual foram realizados os testes com o simulador de escoamento

\begin{tabular}{|c|c|c|c|c|c|}
\hline \multicolumn{3}{|c|}{ Granulometria (dag kg ${ }^{-1}$ ) } & \multirow{2}{*}{$\begin{array}{c}\text { Retido na } \\
\text { peneira } 200(\%)\end{array}$} & \multirow{2}{*}{$\begin{array}{c}\text { Massa } \\
\text { específica }\left(\mathrm{kg} \mathrm{dm}^{-3}\right)\end{array}$} & \multirow{2}{*}{ IP* } \\
\hline Argila & Silte & Areia & & & \\
\hline 62,75 & 6,23 & 31,02 & 30,76 & 1,30 & 20,64 \\
\hline
\end{tabular}

A tensão aplicada foi determinada através da seguinte equação:

$$
\tau_{\mathrm{E}}=\frac{\gamma \mathrm{y} S}{0,102}
$$

em que

$\tau_{\mathrm{E}}$ - tensão provocada pelo escoamento, $\mathrm{Pa}$

$\gamma$ - peso específico da água, $\mathrm{kgf} \mathrm{m}^{-3}$

$\mathrm{y}$ - profundidade do escoamento, $\mathrm{m}$

$\mathrm{S}$ - declividade do canal, $\mathrm{m} \mathrm{m}^{-1}$

Tendo em vista a dificuldade para a medição direta da lâmina d'água no canal, esta foi determinada utilizando-se a equação de Manning com coeficiente de rugosidade para canal de terra limpo já tendo sofrido intemperismo $(n=0,022)$, condição que mais se aproximou das condições do canal. A vazão aplicada no canal foi controlada por meio de válvulas instaladas na saída da caixa para controle de nível. A vazão de cada válvula foi calibrada usando-se, para tanto, o método direto, considerando-se a abertura total da válvula. Obteve-se, desta forma, para cada nova vazão, outra lâmina de escoamento e, conseqüentemente, outro valor de tensão aplicada.

A declividade do canal foi obtida pela diferença de nível entre o início e o final da área exposta ao escoamento no interior da calha (Figura 2). O tempo previsto para a aplicação de cada vazão foi tomado em função do volume a ser armazenado. $\mathrm{Na}$ Tabela 2 são apresentados as vazões aplicadas, o tempo de aplicação e o volume armazenado. Os testes foram realizados procurando-se simular o ramo ascendente de um hidrograma, iniciando-se o escoamento com apenas uma válvula aberta e acrescentada nova vazão a cada novo intervalo de tempo. Cada vazão foi direcionada para o sistema de coleta de sedimentos, em um reservatório próprio, com capacidade para $500 \mathrm{~L}$
Tabela 2. Vazões aplicadas, tempo de aplicação e volume armazenado nos testes realizados com o simulador de escoamento

\begin{tabular}{cccc}
\hline $\begin{array}{c}\text { Número } \\
\text { de válvulas }\end{array}$ & $\begin{array}{c}\text { Vazão } \\
\text { calibrada }\left(\mathrm{L} \mathrm{s}^{-1}\right)\end{array}$ & $\begin{array}{c}\text { Tempo previsto } \\
\text { de aplicação (s) }\end{array}$ & $\begin{array}{c}\text { Volume } \\
\text { armazenado (L) }\end{array}$ \\
\hline 1 & 1,90 & 180 & 342,0 \\
2 & 3,83 & 120 & 459,6 \\
3 & 5,95 & 60 & 357,0 \\
4 & 7,94 & 60 & 476,4 \\
\hline
\end{tabular}

armazenando, de maneira independente, os sedimentos advindos para cada nova vazão.

Realizaram-se duas instalações nas mesmas condições de solo, com três repetições. Cada instalação correspondeu a um teste. Após o término de cada teste, o solo erodido foi coletado, utilizando-se uma peneira de malha 200 , sendo o solo erodido para cada vazão quantificado de forma separada, por meio de comparação com os valores obtidos da curva granulométrica do solo do canal (Tabela 1).

\section{Determinação da erodibilidade e tensão crítica de cisalhamento}

Para determinação da erodibilidade e tensão crítica de cisalhamento do solo, foram tomados dados médios de perda de solo obtidos nos testes. Esses dados foram plotados em um gráfico de perda de solo versus tensão aplicada, fazendo-se o ajuste de uma equação ao conjunto de pontos.

A erodibilidade do solo foi obtida pela inclinação da linha de tendência dos dados obtidos, enquanto a tensão crítica de cisalhamento o foi por meio de projeção da linha de tendência dos pontos de perda de solo até o eixo $\mathrm{X}$, ou seja, perda de solo nula.

\section{RESULTADOS E DISCUSSÃO}

Para análise do desempenho do equipamento foram considerados tantos aspectos construtivos e operacionais, como os resultados obtidos dos testes realizados.

\section{Aspectos construtivos e operacionais}

$\mathrm{O}$ equipamento é bastante simples, uma vez que não apresenta dispositivos eletrônicos ou elétricos, sendo o controle de vazão realizado manualmente. A instalação do equipamento também se mostrou bastante simples, porém foram observados problemas que podem limitar seu uso, os quais são apresentados na seqüência:

- necessidade de grande quantidade de mão-de-obra, sendo necessário no mínimo quatro pessoas para realização do teste;

- tendo em vista o fato do sistema funcionar por gravidade, a realização do teste só é possível em locais com estrada em declive ou com a presença de "barrancos" laterais, que possibilitem uma diferença de nível entre o reservatório de água e aquela para controle de nível;

- o elevado consumo de água nos testes faz com que haja necessidade do transporte de grande volume de água. Para cada teste realizado foram consumidos aproximadamente $2000 \mathrm{~L}$;

- a adaptação do equipamento é boa em canais cujo leito seja suficientemente largo para que a calha permaneça em 
posição próxima à horizontal; entretanto, sua instalação apresenta dificuldades para canais com seção irregular.

A estrutura cortante para cravar a calha no solo e evitar vazamentos mostrou-se eficiente, pois não ocorreu vazamento sob a mesma; além disso, a espuma aderida à calha junto à estrutura cortante evitou que o escoamento atingisse o solo perturbado.

\section{Valores de erodibilidade e de tensão crítica de cisalhamento}

$\mathrm{Na}$ Tabela 3 são apresentados os valores de declividade do canal na calha, tensão aplicada e perda de solo ocorrida em dois testes realizados com o equipamento e, na Tabela 4, temse os valores médios de vazão, tempo de aplicação e tensão aplicada, considerando-se os dois testes e a perda de solo média para cada tensão aplicada. Na Figura 5, apresenta-se a curva de perda de solo por tensão aplicada e o valor da erodibilidade obtido com os dados apresentados na Tabela 4.

Tabela 3. Dados médios de perdas de solo pertinentes aos testes de campo

\begin{tabular}{cccc} 
Teste & $\begin{array}{c}\text { Declividade } \\
(\%)\end{array}$ & $\begin{array}{c}\text { Tensão } \\
\text { aplicada }(\mathrm{Pa})\end{array}$ & $\begin{array}{c}\text { Perda } \\
\text { de solo }\left(\mathrm{g} \mathrm{min}^{-1} \mathrm{~cm}^{2}\right)\end{array}$ \\
& & 10,51 & 0,00551 \\
1 & 5,60 & 16,75 & 0,00399 \\
& & 22,69 & 0,00721 \\
& & 27,29 & 0,00652 \\
\hline \multirow{3}{*}{2} & \multirow{3}{*}{6,13} & 11,17 & 0,00278 \\
& & 17,79 & 0,00631 \\
& & 24,07 & 0,00769 \\
& & 29,50 & 0,00621 \\
\hline
\end{tabular}

Tabela 4. Dados médios de perdas de solo referentes aos testes de campo

\begin{tabular}{cccc}
\hline $\begin{array}{c}\text { Vazão } \\
\left(\mathrm{L} \mathrm{s}^{-1}\right)\end{array}$ & $\begin{array}{c}\text { Tempo } \\
(\mathrm{min})\end{array}$ & $\begin{array}{c}\text { Tensão } \\
(\mathrm{Pa})\end{array}$ & $\begin{array}{c}\text { Perdas de solo médias } \\
\text { acumuladas }\left(\mathrm{g} \mathrm{min}^{-1} \mathrm{~cm}^{-2}\right)\end{array}$ \\
\hline 1,90 & 3,21 & 10,84 & 0,00414 \\
3,83 & 1,90 & 17,27 & 0,00929 \\
5,95 & 1,02 & 23,38 & 0,01674 \\
7,94 & 0,96 & 28,39 & 0,02311 \\
\hline
\end{tabular}

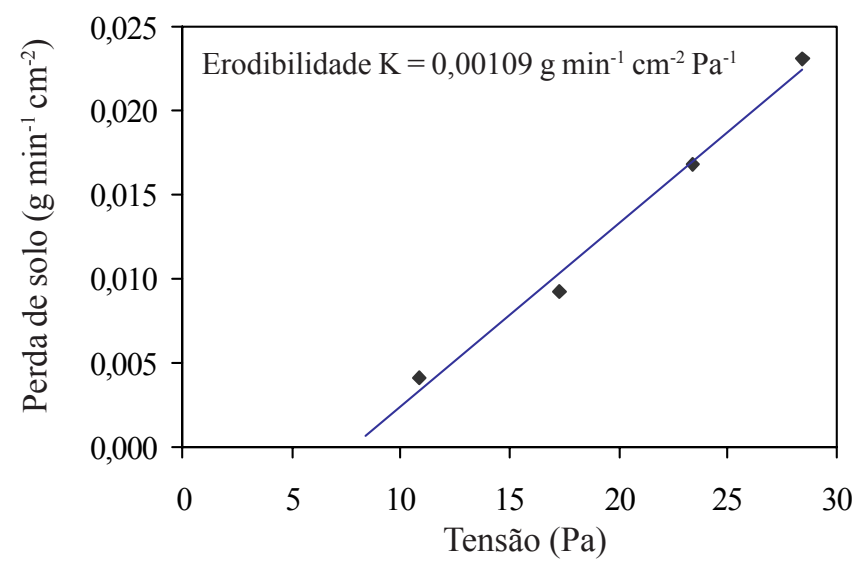

Figura 5. Erodibilidade $\left(\mathrm{g} \mathrm{cm}^{-2} \mathrm{~min}^{-1} \mathrm{~Pa}^{-1}\right)$ obtida a partir dos dados de perda de solo determinados com o simulador de escoamento
O valor de erodibilidade obtido $\left(\mathrm{K}=0,00109 \mathrm{~g} \mathrm{~cm}^{-2} \mathrm{~min}^{-1} \mathrm{~Pa}^{-1}\right)$ apresenta-se bastante próximo ao valor apresentado por Morfin et al. (1996), para solo argiloso $\left(0,0012 \mathrm{~g} \mathrm{~cm}^{-2} \mathrm{~min}^{-1} \mathrm{~Pa}^{-1}\right)$; no entanto, um pouco abaixo daquele obtido para solos arenosos. Este fato se justifica, uma vez que o canal no qual o teste foi realizado se encontrava bastante próximo à pista de rolamento, indicando que este pode ter sofrido compactação em razão do trânsito de veículos. Tal fato pode justificar também a elevada tensão crítica de cisalhamento obtida $(7,5 \mathrm{~Pa})$, bastante superior àquela apresentada por Morfin et al. (1996) para condição de solo argiloso $(1,5 \mathrm{~Pa})$.

\section{CONCLUSÕES}

1. O equipamento mostrou-se adequado para simular o escoamento superficial sob condições de canal de estradas.

2. O equipamento mostrou-se adequado para a obtenção da erodibilidade e tensão crítica de cisalhamento.

3. O simulador de escoamento necessita de ajustes, de modo a aumentar sua praticidade, visando à redução da mão-de-obra necessária à execução dos testes, adaptação a diferentes seções de canais, além de permitir a recirculação de água.

\section{LITERATURA CITADA}

Anjos Filho, O. Estradas de terra. Jornal O Estado de São Paulo, São Paulo. Suplemento agrícola, 29 de abril de 1998.

Bastos, C.A.B. Estudo geotécnico sobre a erodibilidade de solos residuais não saturados. Porto Alegre: Universidade Federal do Rio Grande do Sul, 1999. 256p. Tese Doutorado

Denardin, J.E. Erodibilidade do solo estimada por meio de parâmetros físicos e químicos, Piracicaba: ESALQ, 1990. 113p. Tese Doutorado

Fácio, J.A. Proposição de uma metodologia de estudo da erodibilidade dos solos do Distrito Federal. Brasília: Universidade de Brasília, 1991. 107p. Dissertação Mestrado

Fragassi, P.F.M. Estudo da erodibilidade dos solos residuais de Gnaisse da Serra de São Geraldo e de Viçosa (MG). Viçosa: UFV, 2001. 119p. Dissertação Mestrado

Grace III, J.M.; Rummer, B.; Stokes, B.J.; Wilhoit, J. Evaluation of erosion control techniques on forest roads. Transactions of the ASAE, St Joseph, v.41, n.2, p.383-391, 1998.

Hollick, M. Towards a routine test for the assessment of the critical tractive forces of cohesive soils. Transactions of the ASAE, St. Joseph, v.19, n.6, p.1076-1081, 1976.

Kamphuis, J.W.; Gaskin, P.N.; Hoogendoorn, E. Erosion tests on four Ontario clays. Canadian Geotechnical Journal, Ottawa, v.27, p. 692-696,1990.

Morfin, S.; Elliot, W.; Foltz, R.; Miller, S. Predicting effects of climate, soil, and topography on road erosion with the WEPP model. ASAE Annual International Meeting, Phoenix, Arizona. 1996. 12p.

Nogami, J.S.; Villibor, D.F. Pavimentação de baixo custo com solos lateríticos. São Paulo: Villibor, 1995. 240p. 